ARCHIVO ESPAÑOL DE ARTE, XCIII, 370

ABRIL-JUNIO 2020, pp. 153-160

ISSN: 0004-0428, eISSN: 1988-8511

https://doi.org/10.3989/aearte.2020.11

\title{
ENCARGOS ARTÍSTICOS DE JUANA CORTÉS (1538-1588), II DUQUESA DE ALCALÁ*
}

\author{
SERgio RAMiro RAMÍREZ ${ }^{1}$ \\ Universidad Complutense de Madrid
}

\begin{abstract}
El artículo analiza un libro de finiquitos inédito que recoge los pagos realizados por Juana Cortés, II duquesa de Alcalá, en nombre de su madre Juana de Zúñiga (†1583). El documento atestigua su activa participación en el encargo de sendos monumentos funerarios para su madre y su hermana Catalina.

Palabras clave: Patronazgo femenino; siglo XVI; Sevilla; Juana Cortés; Convento de Madre de Dios; Diego de Pesquera.
\end{abstract}

\section{ARTISTIC COMISSIONS BY JUANA CORTÉS (1538-1588), II DUCHESS OF ALCALÁ}

The paper analyses an unpublished log of payments made by Juana Cortés, II Duchess of Alcalá, on behalf of her mother Juana de Zúñiga. It attests to her active involvement in the commission of two burial monuments for both her mother and her sister Catalina.

Key words: Female Patronage; Sixteenth Century; Seville; Juana Cortés; Diego de Pesquera.

Cómo citar este artículo / Citation: Ramiro Ramírez, Sergio (2020): "Encargos artísticos de Juana Cortés (15381588), II duquesa de Alcalá". En: Archivo Español de Arte, vol. 93, núm. 370, Madrid, pp. 153-160. https://doi. org/10.3989/aearte.2020.11.

Juana Cortés Ramírez de Arellano (1538-1588) fue la más joven de los seis hijos de los I marqueses del Valle: Hernán Cortés (1485-1547) y Juana Ramírez de Arellano y Zúñiga (†1583). $\mathrm{Su}$ figura ha gozado de poca fortuna en los estudios históricos, cuestión que dificulta el rastreo de noticias sobre su vida. De hecho, es muy elocuente que para esta tarea sea necesario acudir a los trabajos relacionados con su padre o la familia política de su esposo, Fernando Enríquez de Ribera (1527-1594) heredero del ducado de Alcalá, con el que contrajo matrimonio el 22 de enero de 1564 en la iglesia de San Benito de Calatrava de Sevilla² .

Tal y como nos recuerda Mallén Herráiz, el II duque de Alcalá continúa siendo una figura borrosa que no ha gozado de la fortuna crítica de su predecesor ni de su sucesor en el título ${ }^{3}$, una imagen que además ha redundado negativamente en el interés prestado a su esposa. Por otro lado, como tendremos ocasión de comprobar en las páginas sucesivas, a pesar de que Juana Cortés puso un gran empeño en la construcción de unas sepulturas monumentales para su madre y su hermana Catalina, su nombre no apareció en las escrituras públicas de estos encargos, forma-

\footnotetext{
${ }^{*}$ Este trabajo ha sido elaborado en el marco del proyecto I+D+i MICINN/FEDER [HAR2015-65166-P] «Femenino singular: Las mujeres y las artes en la Corte española en la Edad Moderna (reinas, nobles, artistas y empresarias)».

1 serramir@ucm.es / ORCID iD: http://orcid.org/0000-0002-4201-4780

2 González Moreno, 1969: 36-37.

3 Mallén Herráiz, 2018: 388, nota 7.
}

Copyright: (C) 2020 CSIC. Este es un artículo de acceso abierto distribuido bajo los términos de una licencia de uso y distribución Creative Commons Reconocimiento 4.0 Internacional (CC BY 4.0) 
lizadas por su marido, por lo que la historiografía nunca le ha adscrito un papel activo en la agencia artística de la Sevilla de mediados del siglo XVI. Paradójicamente, a todo ello se ha sumado la desaparición de su propia sepultura en la Cartuja de Santa María de las Cuevas, panteón de los Enríquez de Ribera, contribuyendo a que su memoria se haya diluido en la historia de ambos linajes.

$\mathrm{Su}$ boda vino motivada por la inminente salida hacia América de su hermano Martín, quien pretendía colocarse al frente de los estados del mayorazgo familiar y trasladar los restos de su padre desde San Isidoro del Campo hasta el monasterio de San Francisco en Texcoco. El primogénito abandonó Sevilla en 1566, pero, a diferencia de lo que podría pensarse, el matrimonio de Juana no la alejó de los asuntos de su familia biológica. De hecho, durante la ausencia de Martín, Juana sustituyó a su hermano al frente del linaje en Castilla, como es posible deducir a la luz de unos documentos custodiados en el Archivo Ducal de Medinaceli, en cuyo Fondo Histórico se conservan dos copias de los libros de cuentas manejados por Juana Cortés, titulados ambos como "Libro de finiquitos de mi señora la marquesa del Valle a mi señora la duquesa de Alcalá"4. Estas cuentas demuestran que, durante años, la duquesa administró los encargos y adquisiciones de su madre realizados con los fondos que anualmente su hermano enviaba desde América, obligado a ello tras una concordia firmada en 1550. Así, sabemos que Juana gestionó unas remesas de plata que alcanzaron cantidades muy altas, como parte de los tres millones de maravedíes que cada año debía enviar Martín ${ }^{5}$. Este capital situó a la marquesa viuda del Valle como una de las más acaudaladas personalidades de la Sevilla de su tiempo.

De esta manera, la documentación aquí analizada recoge la recepción anual del metal precioso y los pagos que Juana Cortés realizó desde el año 1567 hasta el 6 de septiembre de 1581, cuando finalizan dos años antes de la muerte de la marquesa el 2 de diciembre de 1583. Las razones por las que Juana Cortés manejó este patrimonio nos son desconocidas, aunque entendemos que existía una incapacidad de su hermana mayor Catalina para hacerse cargo de los asuntos familiares ${ }^{6}$.

Entre otras cuestiones, gracias a estos registros podemos reconstruir los abonos a los alarifes que trabajaron en la mejora de los ambientes domésticos de la casa de su madre en Santa Clara, así como sus gestiones para adquirir una nueva residencia en la collación de San Vicente, comprada a Santiago de los Caballeros. De mucho interés es la labor que Juana desarrolló en el embellecimiento del oratorio de su madre, con encargos particulares de series completas de lienzos (no se especifica cuántos), que representaban la historia de Moisés por nueve ducados pagados entre 1565 y 1566 (fol. 1v). Igualmente, el 4 de enero de 1573 Juana Cortés adquirió para este espacio un ornamento de imaginería y unos almaizares, es decir telas ricas, con los que se cubrirían algunas partes de él.

También aparece consignada en 1567 la compra de una escultura dorada de la Virgen María valorada en 6 ducados (fol. 13v), una imagen de oro de Santo Domingo por 20 ducados que Juana Cortés mandó fundir el 22 de octubre de 1574 (Fol. 66r) y una cruz de Santo Toribio de oro en marzo de ese año. Asimismo, reclama nuestra atención el corazón de oro (fol. 38r) que compró para la marquesa en 52 reales y que debió estar ligado a los exvotos que se solían depo-

\footnotetext{
4 Las transcripciones de este artículo provienen del libro Quaderno de quentas y finiquitos de partidas de maravedis que mi señora la marquesa del Valle rescibio, i gasto de mi señora la duquesa doña Juana de Cortes, 1567-1581, Archivo Ducal de Medinaceli, Toledo (ADM), fondo histórico, legajo 175, núm 8. La signatura de la copia es ADM, Fondo Histórico, legajo 175, (44-49) Olim letra 9, núm. 7.

5 López Martínez, 1948: 70 y ss.

${ }^{6}$ Con anterioridad al nacimiento de Juana, Hernán Cortés fundó un mayorazgo el 9 de enero de 1535 en el que se nos dice que en esos momentos la niña está bajo la tutoría de Juana de Zúñiga porque se le nombra como "la qual tiene la Marquesa mi mujer en su poder": Cláusulas del mayorazgo de Fernán Cortés primero marques del Valle, General de la Nueva España, Biblioteca Nacional de España, Madrid (BNE), VE/28/13, fol. 1v. Esta forma de referirse a Catalina en el mayorazgo, su soltería y el modo en el que Juana hubo de gestionar la mayoría de los asuntos relacionados con su madre nos hace pensar que Catalina no se encontraba en plenas facultades y se mantuvo siempre bajo la tutoría de su madre y su hermana.
} 
sitar en la Catedral de Sevilla ante la Virgen de la Antigua desde finales del siglo XV ${ }^{7}$. La factura de estas obras corresponde a los plateros que trabajaron para el entorno de ambas mujeres, pues en estos registros nos aparecen adquisiciones a Fernando de Córdoba, Francisco López, Julio García Bejarano, Cristóbal López, Pero Rodríguez o Juan Macías, como artífices que trabajaron asiduamente para ellas.

Por el contrario, casi nada sabemos del aspecto del tríptico que compró Juana en nombre de su madre, más allá de que tenía dos puertas y que estaba tasado en 55 reales (fol. 15r). Tampoco se exponen muchos detalles, más allá de su relación y precio, de los candeleros para el altar, una lámpara de plata, un aguamanil, un crucifijo de plata, relicarios del mismo metal o las vinajeras con sus platillos que aparecen consignados, aunque el documento nos permite dudar de si algunos de estos objetos fueron adquiridos para el oratorio personal de Juana de Zúñiga o para la proyectada capilla funeraria que esta preparaba por aquel entonces, ya que en el libro de finiquito correspondiente al año 1567 se advierte que su hija Juana Cortés costeó la confección de once guadamecíes provenientes de Córdoba con "medallas de muertes" que sumaron la nada despreciable cantidad de 66 ducados (fol. 12r).

Como se ha mencionado con anterioridad, Juana Cortés se afanó poco después en la configuración del enterramiento monumental de su madre y su hermana Catalina en el Monasterio de Madre de Dios, donde la marquesa del Valle adquirió los derechos de patronazgo sobre la capilla mayor de su templo en $1570^{8}$. Aprovechando que a mediados del siglo XVI las religiosas necesitaban reformar la precaria situación de la iglesia, Juana de Zúñiga ofertó 3.500 ducados para la construcción de la capilla mayor y la cripta en la que reposarían los cuerpos, 2.000 ducados para el retablo del altar y otros 20.000 maravedís destinados al mantenimiento del culto, que podían gastarse tanto en oficios religiosos como en ornamentos ${ }^{9}$. A cambio, se les concedió el derecho de enterrarse en ella, privilegio que finalmente ejerció, como veremos, junto a Catalina fallecida en 1565 y su nuera Ana de Arellano, esposa de Martín Cortés, el 17 de abril de $1578^{10}$.

Las nuevas obras de la iglesia finalizaron en 1572, pero el ornato completo del templo se extendió hasta $1598^{11}$. En ella intervinieron algunos de los artífices mejor dotados entre los disponibles en Sevilla durante el siglo XVI, como el maestro mayor de carpintería del Alcázar Juan de Simancas o el escultor Jerónimo Hernández (†1586), autor del retablo original costeado también por Juana de Zúñiga y ejecutado entre 1570 y $1573^{12}$.

7 Pereda, 2007: 185-186.

${ }^{8}$ López Martínez, 1948: 94. Los orígenes del cenobio se remontan a 1476, cuando Isabel Ruiz de Esquivel fundó un beaterio en un hospital, bajo la advocación de San Cristóbal, junto a la puerta de Triana. Sin embargo, la comunidad hubo de trasladarse tras una riada en 1485 que dañó gravemente el edificio. Con este fin, la reina Isabel concedió a las religiosas la propiedad sobre unas casas principales situadas en la collación de San Nicolás, cuyos anteriores dueños habían sido procesados por judaizantes: Gestoso y Pérez, 1984: 6.

${ }^{9}$ Además de la importante contribución de Juana de Zúñiga, las obras se habían financiado con la participación de personajes enriquecidos con los negocios de la monarquía en América, entre las que destacan la profesión en el convento de tres hijas de los condes de Gelves, a su vez bisnietas de Colón, o el patronazgo de la familia Venegas en su capilla: López Martínez, 1948: 39.

${ }^{10}$ López Martínez, 1948: 58. Martín Cortés hizo mención a su primera esposa, Ana de Arellano, en su testamento firmado en Madrid a 11 de agosto de 1589. Martín se encontraba en ese momento casado con Magdalena de Guzmán y ordenó que, en el que caso de que su esposa no dispusiese su entierro junto a él tal y como habían acordado, se trasladasen sus restos hasta México junto a los de Ana de Arellano, los cuales estaban depositados en el Monasterio de Madre de Dios de Sevilla. Allí debían reposar junto a los de Hernán Cortés en el Hospital-Panteón que tenía ordenado construir: Testamento de Martín Cortés, Archivo Histórico de Protocolos de Madrid, Madrid (AHPM), legajo 1398, fols. 493-504.

11 Valdivieso / Morales, 1991: 104.

12 Desgraciadamente, esta primera máquina fue sustituida a comienzos del siglo XVIII por uno nuevo más acorde a la nueva estética del momento, por lo que del primer trabajo de Hernández solo se reaprovecharon el relieve con la última Cena, la Virgen del Rosario de la hornacina principal, ambas en la calle central, y el Calvario que corona el conjunto, a los que es posible sumar un Santo Domingo de Guzmán y una Santa Catalina de Siena conservadas en el coro bajo, así como un Cristo resucitado en una dependencia contigua al coro alto: Valdivieso / Morales, 1991: 105, 107 y 108. Calderón / Calderón, 2004: 82-87. 
De este modo, gracias a las cuentas que aquí se presentan, podemos confirmar que las obras en la capilla mayor iban a buen ritmo en 1571, porque Juana Cortés pagó 5.500 ducados ese mismo año, es decir los 3.500 de la obra más los 2.000 del nuevo retablo, y compró un paño de terciopelo negro "para encima de la tumba que está puesta en la dicha capilla" (fol. 39r), a los que se sumaron una tela de oro para coser una cruz sobre ella, tela de Milán para forrarlo, seda y cuatro escudos bordados que debía contener. Otra mención a la celeridad con la que se ejecutaban las obras es otra entrada de esa anualidad que recoge un pago de 890 reales y medio por el traslado de unos huesos no identificados desde el Monasterio de San Pablo. Encontramos nuevas referencias durante el último año de realización del retablo, como los trescientos reales que pagó a su criado Sotomayor en 6 de mayo de 1573 para sufragar el gasto de vidrieras e hierros que lo constituían y parte de 200 reales destinados a "acabar de pagar los aderezos del dicho retablo" (fols. 55v y 56r). Asimismo, el 22 de marzo de 1574, Juana Cortés abonó 718 reales a "Valera rejero por el pasamano que hizo para la capilla" (fol. 68r).

En la elección de los artistas también es posible intuir la participación de Juana Cortés. Jerónimo Hernández debió ser un artífice asiduo en las obras encargadas por la familia, al menos conocido por los duques, lo que explica su comparecencia en las obras del monasterio. El escultor era también vecino de San Juan de la Palma ${ }^{13}$, donde estaba situado el Palacio de Dueñas, y años antes el artista había participado en la finalización del retablo de la Cartuja de Santa María de las Cuevas ${ }^{14}$. Por otro lado, el contrato del retablo de Madre de Dios también revela la presencia en el trabajo de Juan de Oviedo y Hernández ${ }^{15}$. Este último fue el padre del más afamado Juan de Oviedo y de la Bandera (1565-1625), encargado de realizar la portada de la iglesia.

Estas conexiones de artistas que trabajaron para estas mujeres nos llevan a preguntarnos si no fueron ellas las que dispusieron y, en ocasiones, favorecieron las relaciones tradicionales entre las familias y los artífices. Esta cuestión que siempre ha sido atribuida a los hombres, a veces debido a una lectura apoyada en documentos que solo reflejan, en última instancia, quién estaba capacitado legalmente para firmar escrituras, puede ser explorada y matizada con el manejo de los registros privados como los que aquí se presentan, por desgracia raramente conservados. Así, para completar el conjunto, Juana de Zúñiga había encargado también a su hija que se ocupase de gestionar otros detalles de la capilla con su propio dinero, al que se sumó el consignado en su testamento de 9 de septiembre de 1579 donde dispuso que se diesen a Juana cuatro mil ducados "para que los gaste en las cosas que yo con ella tengo comunicado", al tiempo que encareció la realización de las dos esculturas que debían presidir la sepultura, junto a dos candeleros y una cruz de plata "del peso y hechura que la duquesa de Alcalá mi hija pareciere" 16 .

Igualmente, la historia de estos sepulcros corrobora la intervención directa de Juana Cortés en la primera parte de este proyecto, cuidando hasta su muerte de la culminación exitosa de un proyecto monumental para su madre y su hermana. Actualmente, en los muros laterales de la capilla mayor se encuentran las sepulturas aludidas realizadas en 1590 por Juan de Oviedo y Miguel Adán; pero, como es sabido, estos no responden a la idea original, pues la primera noticia de este encargo se remonta a 1575, cuando el II duque de Alcalá contrató con el escultor Diego de Pesquera la hechura de dos estatuas orantes sobre cojines representando a Juana de Zúñiga - vestida de viuda frente a un sitial con un libro abierto - y su hija Catalina, con ropas de doncella y sosteniendo otro libro de horas ${ }^{17}$.

13 López Martínez, 1948: 20. Sobre su trayectoria, véase Palomero Páramo, 1981.

${ }^{14}$ Sin embargo, años más tarde testificó contra el II duque de Alcalá en el interrogatorio del pleito iniciado por el patrón en 1585 contra la Cartuja: Testimonio de las diligencias hechas por parte del Monasterio de la Cartuja en el pleito que trató con el señor duque don Fernando sobre querer que el dicho señor no fuese patrono de ellas, ADM, Fondo histórico, legajo 250, núm. 9, fol. 72r y Jerónimo Hernández, 1986: 4.

15 Asimismo, Juan de Oviedo contrató en 1572 la sillería del coro de la iglesia: López Martínez, 1929: 78-79.

${ }^{16}$ López Martínez, 1948: 88.

17 López Martínez, 1929: 86-88. 


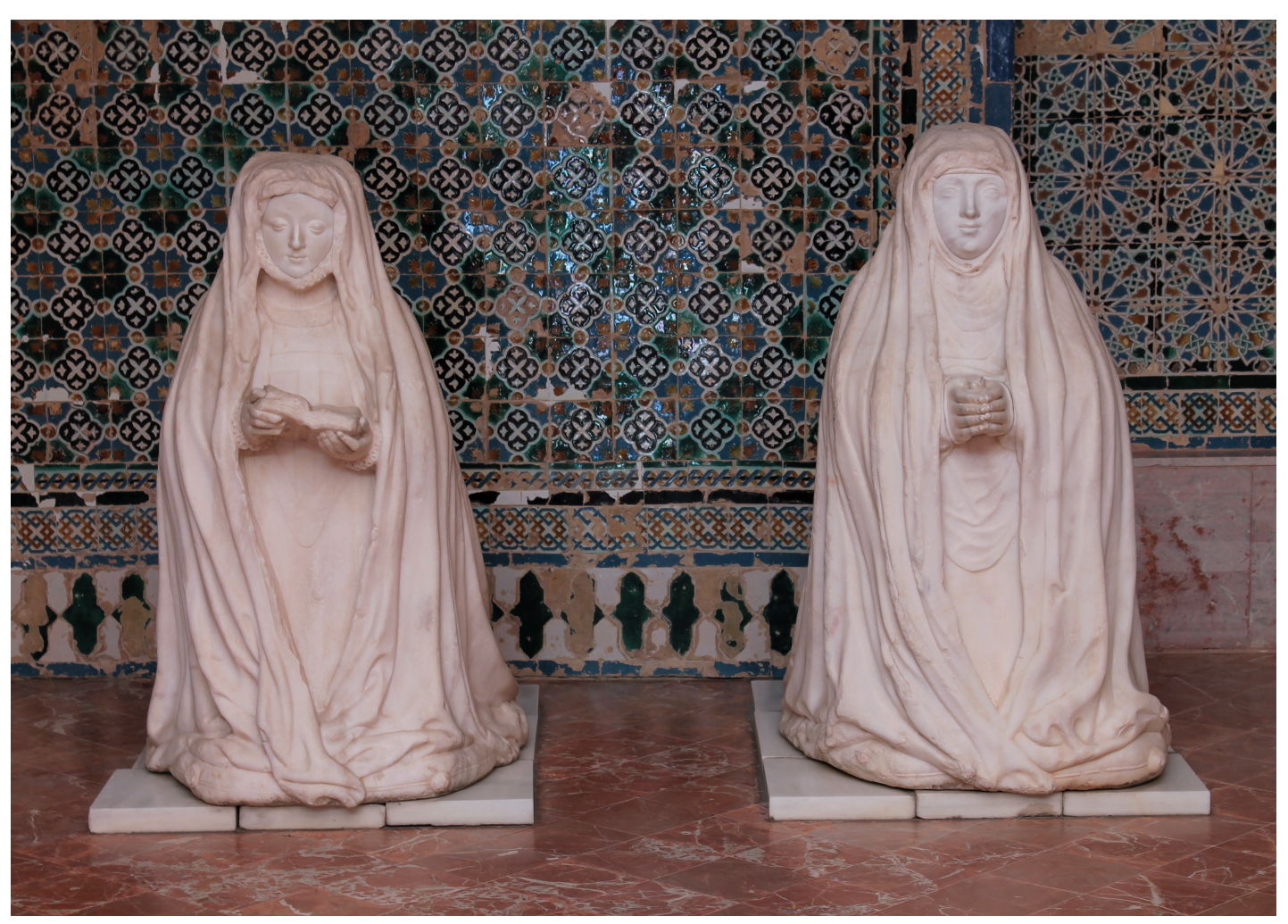

Fig. 1. Diego de Pesquera: Esculturas orantes de Catalina Cortés y Juana de Zúñiga, 1575-1577, Sevilla, Cartuja de Santa María de las Cuevas. Foto.: David Mallén Herráiz.

Pesquera había llegado a la ciudad cuatro años atrás proveniente de Granada. Allí había trabajado en la catedral de la que se convirtió en su imaginero, pero no parece que formase parte de ese círculo de artistas que, en un primer momento, puedan relacionarse con los Alcalá. De hecho, aunque el contrato público con Pesquera fue formalizado por el duque de Alcalá, en la decisión de contratar al escultor hubo de intervenir necesariamente Juana Cortés, encargada de gestionar el patrimonio materno, al igual que de la elaboración de la platería de la capilla que debía seguir sus instrucciones. Aunque desconocemos el grado de responsabilidad que cabe imputarle en la decisión final, existe una diferencia notable entre el primer proyecto de Pesquera, una solución compositiva audaz y dinámica en las que las efigiadas se representaban con una actitud activa, frente a la postura yacente que finalmente se impuso tras la muerte de nuestra protagonista y que las hace invisibles desde las naves de la iglesia.

En los libros de cuentas anteriormente citados, Juana consignó puntualmente el dinero empleado en este encargo. El primer pago se efectuó un día antes de la formalización del contrato, el 24 de septiembre de 1575, por 2.200 reales "en cuenta de los bultos que hace en la Madre de Dios" (fol. 72r), de lo que se deduce que ya estaban acordados antes de la fecha de la escritura pública. Los trabajos debieron avanzar durante los siguientes meses porque, a 25 de abril de 1576, libró otro pago por 200 ducados al artista (fol. 73r). Sin embargo, en 1577 surgieron problemas que nos son desconocidos y el encargo se detuvo, ya que en las cuentas aparecen registros sobre el pago a un procurador que gestionaba "el pleito de los bultos" (fol. 80r), es decir, afloraron desavenencias que desembocaron en una denuncia por parte de la clienta y su hija. El listado sigue indicando a 21 de septiembre de ese mismo año nuevas entregas de dinero, en concreto 44 reales, a un Licenciado Villalobos, servidor de los duques de Alcalá, para continuar el pleito con el escultor (fol. 88v) y el 8 de octubre de 1578 la Audiencia hubo de fallar una sentencia en favor del artista porque Juana Cortés pagó 200 ducados "a Pesquera escultor a cumplimiento de los seiscientos ducados de los bultos que de el se compraron para la Madre de Dios". Después de 
este pleito, cuya documentación se encuentra en paradero desconocido. Pesquera está documentado en 1580, cuando desapareció de Sevilla y marchó a América ${ }^{18}$.

Las piezas que inició Pesquera se han reconocido en las estatuas situadas a día de hoy en la Cartuja de las Cuevas de Sevilla, ambas figuras orantes en mármol [fig. 1]. Efectivamente, Juana de Zúñiga está ataviada con tocas de viuda y, al igual que su hija, su figura está cubierta por un manto. Por su parte, Catalina aparece en hábito de doncella, apenas esbozado en la lechuguilla que le asoma sobre el alto cuello de la saya castellana. Según escribió González Moreno en un artículo aparecido en ABC en 1972, el escultor José Luis Vasallo las restauró tras su redescubrimiento en 1953, lo que es especialmente visible en las manos y en los ros$\operatorname{tros}^{19}$. A la vista de su estado actual, es necesario interrogarse si el pleito se inició por posibles errores en la talla de las esculturas por parte del maestro o, quizá, por la lentitud demostrada durante el proceso. No obstante, su condición de obras inacabadas, en la que debió existir una gran participación del taller, no evita que podamos hacernos una idea de cuál hubiera sido el resultado final.

Tras desechar el proyecto de Pesquera, que quedó almacenado durante siglos en la Casa de Pilatos $^{20}$, aún quedaba pendiente culminar el encargo de Juana de Zúñiga. Así, si es constatable la presencia de Juana Cortés en la primera formulación de la idea, también es posible afirmar que antes de fallecer intentó que la gestión dependiese en última instancia de las mujeres de la familia. En efecto, su testamento, contenido en una institución de mayorazgo de 27 de marzo de 1588, señala esta deuda con la memoria de su madre, haciendo hincapié en que los monumentos funerarios no se habían llevado a término. Además, en su última voluntad declaró que ella era la responsable de concluir el encargo de la marquesa del Valle y finalizó solicitando que fuese su hija Catalina la ejecutora de la tarea pendiente y no así su marido:

Ítem declaro que no debo deudas algunas a ninguna persona de ningún género ni calidad que sea por que todo lo he pagado y los albaceas que me han sido encomendados los tengo cumplidos. Así el cargo de albaceas de la marquesa del Valle mi señora como otras cualquier y no me resta de todo ello por hacer y cumplir sino los bultos que la dicha marquesa mi señora mandó hacer y poner en su capilla mayor del Monasterio de la Madre de Dios de esta ciudad y si en vida yo no lo hubiere mandado hacer y poner los dichos bultos mando que los haga hacer y poner doña Catalina Cortés mi hija de los réditos de la mejora en que la dicha marquesa del Valle mi señora la mejoró porque esto es así cuenta y cargo doy facultad a mis albaceas para que ellos y cualquier de ellos sin esperar a la dicha doña Catalina mi hija haga y mande hacer los dichos bultos y tomen y cobren de los dichos réditos lo necesario para ello ${ }^{21}$.

Juana Cortés murió en el mes de mayo de 1588 y en ese mismo testamento solicitó que su cuerpo fuese sepultado junto al del duque en la Cartuja de Santa María de las Cuevas ${ }^{22}$. Finalmente, no sabemos si requerido por su hija Catalina, en 1589 el II duque de Alcalá comisionó a los artistas Juan de Oviedo y de la Bandera y a Miguel Adán que labrasen dos estatuas de mármol de Génova con las efigies de Juana Zúñiga y su hija Catalina, siguiendo el modelo de figuras tumbadas sobre lechos semejantes a la del arzobispo Diego Hurtado de Mendoza en la capilla de la Antigua de la catedral [figs. 2 y 3$]^{23}$.

\footnotetext{
18 Gómez-Moreno Martínez, 1955: 301 y Estella Marcos, 1990: 96.

19 "Hallazgo de dos retratos de la familia de Hernán Cortés. En $A B C$, Sevilla, 21-I-1972: 14. Agradezco a David Mallén Herráiz por señalarme esta noticia y por su siempre amable ayuda en esta investigación. Véase también Morales Chacón, 1996: 93-95.

20 Ibídem.

21 "Fundación de mayorazgo de la señora doña Juana Cortés, duquesa de Alcalá y su testamento autorizado", 23 de marzo de 1588, ADM, Fondo histórico, legajo 250, 7-9.

22 Esta última disposición no pudo cumplirse hasta finales de siglo. Mientras tanto, el cuerpo de Juana junto al de su hijo, el IV marqués de Tarifa fallecido en 1590, estuvo custodiado en la cripta del Monasterio de Madre de Dios: López Martínez, 1948: 95-96.

23 López Martínez, 1943: 24.
} 
Fig. 2. Juan Oviedo y de la Bandera / Miguel Adán: Sepulcro de Juana de Zúñiga, 1590, Sevilla, Monasterio de Madre de Dios.

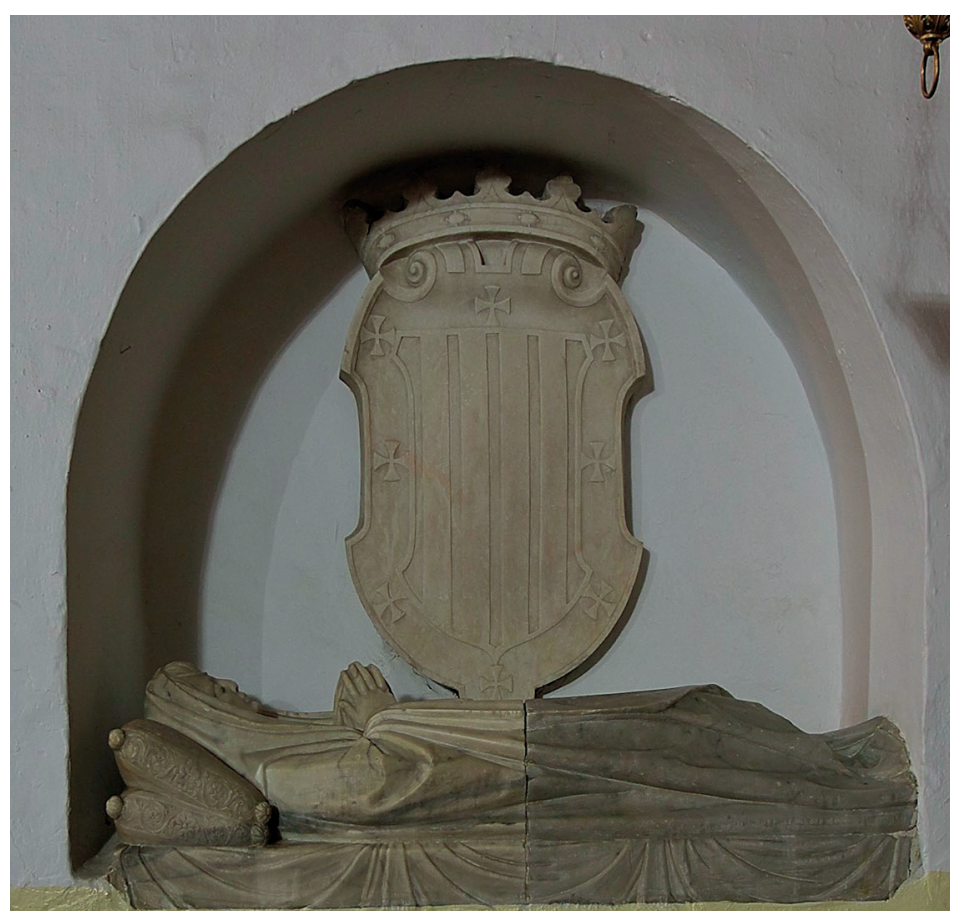

Fig. 3. Juan Oviedo y de la Bandera / Miguel Adán: Sepulcro de Catalina Cortés, 1590, Sevilla, Monasterio de Madre de Dios.

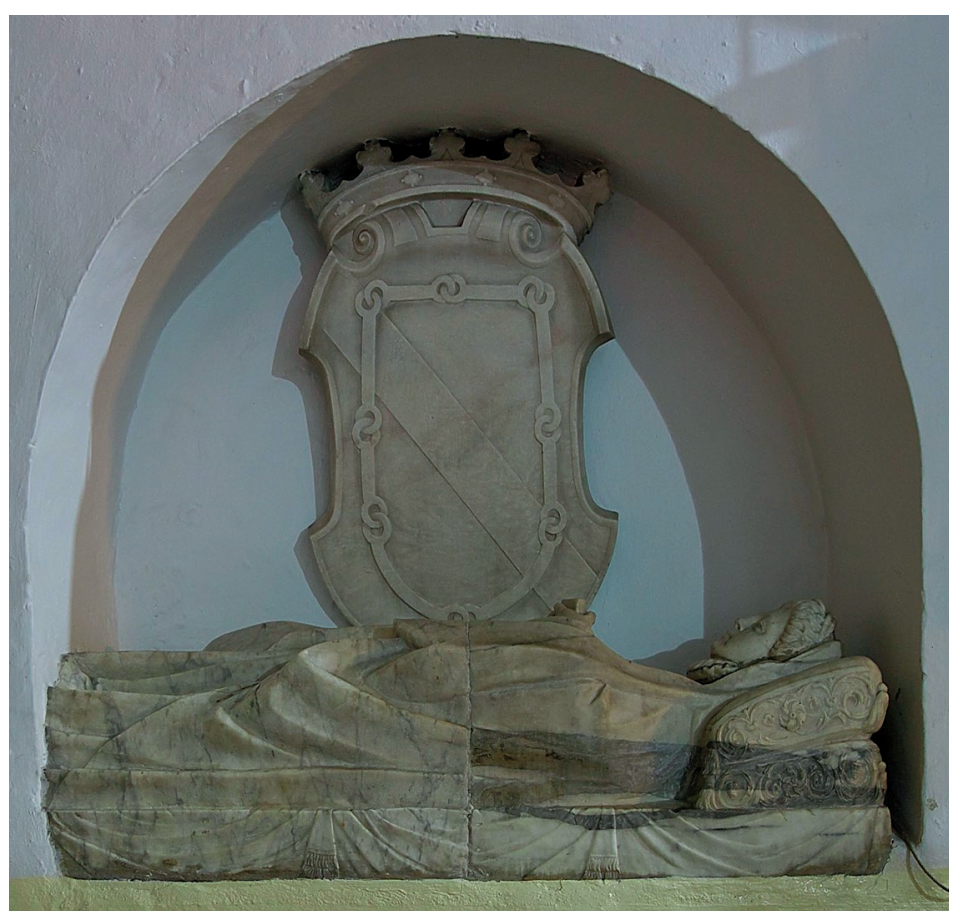

Fallecida Juana Cortés y, probablemente, desentendida su hija de estos encargos, la intervención en solitario del duque de Alcalá denota una solución muy diferente a la adoptada en primera instancia que invita a preguntarnos sobre la toma de decisiones en ambos proyectos y el origen del cambio final. Numerosos factores entraron en juego: la pérdida del dinero, la implicación de artistas diversos o quizás a una solución de compromiso que acelerase su factura y terminara un 
proceso dilatado durante quince años, intervalo durante el cual habían desaparecido las mujeres implicadas en la iniciativa.

\section{BIBLIOGRAFÍA}

Calderón Benjumea, Carmen / Calderón Benjumea, José Antonio (2004): El Real Monasterio de Madre de Dios de Sevilla. Sevilla: Guadalquivir.

Estella, Margarita M. (1990): "Sobre escultura española en América y Filipinas y algunos otros temas". En Arias Anglés, Enrique (ed.), Relaciones artísticas entre España y América. Madrid: CSIC, pp. 73-106

Gestoso y Pérez, José (1984): Sevilla monumental y artística [1889]. Sevilla: Monte de Piedad y Caja de Ahorros de Sevilla.

Gómez-Moreno Martínez, Manuel (1955): “Diego de Pesquera, escultor”. En: Archivo Español de Arte, 112 (t. XXVIII), Madrid, pp. 289-304.

González Moreno, Joaquín (1969): Don Fernando Enriquez de Ribera, tercer Duque de Alcalá de los Gazules (15831637): Estudio biográfico. Sevilla: Ayuntamiento de Sevilla.

Jerónimo Hernández y la escultura del Manierismo en Andalucía y América (1986). Sevilla: Monte de Piedad y Caja de Ahorros.

López Martínez, Celestino (1929): Notas para la Historia del Arte: Desde Jerónimo Hernández hasta Martínez Montañés. Sevilla: Rodríguez Giménez y Cia.

López Martínez, Celestino (1943): El escultor y arquitecto Juan de Oviedo y de la Bandera 1565-1625. Sevilla: Real Academia Sevillana de Bellas Artes de Santa Isabel de Hungría.

López Martínez, Celestino (1948): Descendientes de Cristóbal Colón y de Hernán Cortés en Sevilla y el templo de Madre de Dios de la Piedad. Sevilla: Imprenta Provincial.

Mallén Herráiz, David (2018): "La biblioteca del III duque de Alcalá y el ambiente intelectual sevillano en el siglo XVII". En: Cañestro Donoso, Alejandro (ed.). Scripta Artium in Honorem Prof. José Manuel Cruz Valdovinos. Alicante: Universidad de Alicante, pp. 387-404.

Morales Chacón, Alberto (1996): Escultura funeraria del renacimiento en Sevilla. Sevilla: Diputación Provincial de Sevilla.

Palomero Páramo, Jesús Miguel (1981): Gerónimo Hernández. Sevilla: Excma. Diputación Provincial de Sevilla.

Pereda, Felipe (2007): Las imágenes de la discordia: Política y poética de la imagen sagrada en la España del 400. Madrid: Marcial Pons.

Valdivieso González, Enrique / Morales Martínez, Alfredo J. (1991): Sevilla oculta: monasterios y conventos de clausura. Sevilla: Ediciones Guadalquivir.

Fecha de recepción: 13-VIII-2019

Fecha de aceptación: 06-XI-2019 